\title{
Influence of Gender in the Saving Culture of Sacco Members in Nyandarua County, Kenya
}

\author{
Martin Muriithi ${ }^{1}$, Dennis Muriithi ${ }^{2}$ \\ ${ }^{1}$ School of Business Studies, University of Nairobi, Nairobi, Kenya \\ ${ }^{2}$ Department of Business Administration, Chuka University, Chuka, Kenya \\ Email address: \\ kamuriithi2011@gmail.com (Dennis M.), muriithi03@gmail.com (Martin M.) \\ To cite this article: \\ Martin Muriithi, Dennis Muriithi. Influence of Gender in the Saving Culture of Sacco Members in Nyandarua County, Kenya. Journal of \\ Investment and Management. Vol. 4, No. 1, 2015, pp. 14-24. doi: 10.11648/j.jim.20150401.13
}

\begin{abstract}
Saving is a key component in any development endeavor as it is believed to be the surest way of increasing income and boosting productivity in an attempt to break through the vicious cycle of poverty. A number of studies have demonstrated that the investment and retirement saving behaviors of women and men differ. However, inconsistencies in findings exist in the few studies conducted on the differences in general saving behaviors between men and women. The purpose of this study was to establish gender differences in saving culture with a special bias on SACCO members. Specifically, the study aimed at assessing the influence of income levels on saving culture; evaluate the effect of marital status on saving culture and establish the influence of age on saving culture of SACCO members in Nyandarua County. The research adopted a descriptive survey design and targeted all business and agricultural based SACCO members and officials in Nyandarua County. 18 SACCO officials and 375 SACCO members were sampled using purposive and stratified random sampling respectively. The researcher collected data using structured questionnaires. A descriptive analysis of the data after processing involved computing mean, mode and median with the help of Statistical Package of Social Sciences Software and Microsoft Excel and presented in frequency tables and charts. Marital status of the respondents was found to be statistically significant in terms of the annual saving. The result implies that a change in marital status will affect the annual savings negatively. The researcher is $99.952 \%$ confidence that the change in marital status will negatively have an impact on annual saving. The researcher recommends nurturing of marriage institution as a way of protecting saving culture among women and men members of the SACCO in Nyandarua County.
\end{abstract}

Keywords: Saving Culture, Gender, Income Levels, Financial Decisions

\section{Introduction}

\subsection{Saving Culture}

Saving is deferred spending, a preference to consume tomorrow rather than today (Strydom, 2007). Savings flow into the financial system and help provide funds for investment spending by firms. Tesar (1991) established that, there is a high correlation between savings and investment in the short run and long run. The study also found countries with high saving rates to have high investment rates too.

Saving is a key component in any development endeavor as it is believed to be the surest way of increasing income and boosting productivity in an attempt to break through the vicious cycle of poverty. Without saving people are likely to face severe problem of survival when they are no longer able to work (Wu, 2005). Schmidt and Sevak (2006) argue that when poor households' desire and need to save converge, a safe, easily accessible opportunity to do so, their capacity to save, commitment to saving, and the amounts they manage to save are remarkable. According to a poll conducted by Ipsos-Synovate (2011), only half of Kenyans put money aside regularly as savings. The highest proportion of those who saved came from Nairobi, Central and Rift valley.

Keynes (1936) came up with eight motives which determine the propensity to save and corresponding motives to consumption which turned around the shape of the consumption function. Browning and Lusardi (1996) in their paper reproduced Keynes (1936) eight motives of why people save with an additional ninth. The pre-cautionary motive; individuals save money to enable them deal with unexpected events. The life-cycle motive; households save at specific times in life so as to have sufficient funds available to spend 
on anticipated expenses, like, when starting a family or nearing retirement. The Inter-temporal substitution motive; individuals save to enjoy the returns on savings.

The improvement motive; individuals save with the aim of becoming better by having more to spend. The independence motive; households save with the aim of being self-reliant, not to depend on others for their needs. To enjoy a sense of independence and the power to do things on their own without being questioned. The enterprise motive; to have the capacity and readiness to engage in speculative or business projects. The be-quest motive; intergenerational transfer of wealth. Individuals save so that they can leave behind money when they die. People feel satisfied when they know that their descendants will enjoy their wealth after passing on. The avarice motive; a very strong desire to hold on to what is already yours.

Njung'e (2013) observes that Savings play a major role in economic development since an increase in savings leads to an increase in investment hence improve gross domestic product. If a country saves too little, it means that the households eventually struggle financially and for the broader economy it means that there will be insufficient funds available to finance investment in physical and social infrastructure. Low savings in an economy also means unfavorable growth of the economy, poor job creation and inferior overall living standards relative to nations with a better savings performance.

\subsection{Gender}

Mwangi (2009) defines gender as the socially accepted attributes of an individual related to his or her sex. It is differentiation in any context and treated as such. In the current study it refers to social relationship between men and women, allocation of roles, responsibilities, rights and women obligations in employment. According to Singh and Vinnicombe (2004) the notion of gender should be understood and be related race, class, age, ethnic group among others as cross-cutting variables. Different social-cultural contexts establish gender systems with specific contexts which determine what is valued, expected and allowed in a woman/man and girl/boy.

Through socialization processes, gender roles are learned as they are not fixed but are changeable. Traditions and culture, political, economic, legislation and educations systems institutionalize gender systems. The potential of decision making, control over resources, gender responsibilities/roles are focused on systems and not on individual men and women (Verloo, 2011).

\subsection{Gender and Saving Culture}

A number of studies have shown that the economic wellbeing and financial behaviors of men and women differ significantly. Women hold lower levels of wealth and have significantly lower earnings than men. In addition, women spend as many as five more years than men in retirement as a result of having longer life expectancies. Researchers and financial practitioners have reported that women invest their financial resources more conservatively and are, in general, more risk averse than men (Mulino \& Chai, 2008).

Because the options and constraints that women face in developing economies differ from those of men, their saving behavior may also differ. One of the most important purposes of saving in developing economies is for consumption smoothing purposes (Deaton, 1990). There may be gender differences in responsiveness to this motive. Men who, by their position in the labor market, are more likely to be beneficiaries of social insurance policies may have less need to fall back on savings for consumption smoothing purposes. In his human capital theory, Becker (1975) stated that women rationally choose to invest less than men in human capital, including education, skills, and on-the-job training, affecting women's employment opportunities, incomes, and ability to accumulate wealth. Women make different choices than men due to greater family responsibilities with the gender division of labor within the family, resulting in women taking primary responsibility for household work and child care (Bajtelsmit \& Bernasek, 1996).

\subsection{SACCO Membership in Nyandarua County}

A Savings and Credit Cooperative (SACCO) is a type of cooperative whose objective is to pool savings for the members and in turn provide them with credit facilities. Other objectives of SACCOS are to encourage thrift amongst the members and also to encourage them on the proper management of money and proper investments practices. The Cooperative movement in Kenya dates back to 1931 when the first ordinance to regularize the operations of the cooperatives in the country was enacted. The following decade witnessed increased intervention in the sector with the eventual enactment of the Co-operative Ordinance Act of 1945. However, in 1969 the government required that SACCOs be strictly based on a secure crop or employment relationship. In this "check off system" SACCOs received payments directly from employers, processors (cooperatives, parastatals or private companies) or marketing organizations. This system ensured that a member's income would have automatic deductions to repay loans and was a significant factor in the development of SACCO's. In the case of rural SACCO's, the exclusive right to trade for certain crops conferred on market cooperatives (monopsony) helped this arrangement. However, urban SACCO's proliferated at a much faster rate than rural SACCOs.

Nyandarua County is an administrative county in the former Central Province of Kenya. Its capital town is Ol-Kalou. Nyandarua county has a male population of 292,155, a female population of 304,113 and a total population of 596,268 (2009 Census). Nyandarua County is located on the northwestern part of the Central Province, west of the Aberdare Range. Nyandarua County has a reasonably stable rainfall pattern, which enables subsistence agriculture to be the main economic activity. However there are parts of the district that experience drier conditions. The dominant community in this county is Kikuyu, with other minority groups present especially in the towns. There are 6 SACCOs headquartered in 
Nyandarua County with member base of 14,269 members.

\subsection{Research Problem}

Money saved or invested stands a greater chance of increasing to ensure the financial security of the family. Families' decision to or not to save, how much to save, the frequency of saving, where to save and the forms of saving they engage in are influenced by a multiplicity of factors. Knowledge about the available financial intermediation institutions, safety of the outlet, ease of accessibility, level of return among others are some of the factors that are likely to influence the saving and investment behaviour of families.

A number of studies have demonstrated that the investment and retirement saving behaviors of women and men differ. (Yuh \& Hanna, 1997; Sunden \& Surrette, 1998)Indeed the human capital theory postulates that women rationally choose to invest less than men in human capital, including education, skills, and on-the-job training, affecting women's employment opportunities, incomes, and ability to accumulate wealth $\mathrm{Wu}$, (2005).

However, many economic researchers have focused on differences in income, poverty, and asset accumulation by gender. Inconsistencies in findings exist in the few studies conducted on the differences in general saving behaviors between men and women. For instance, (Sunden \& Surrette, 1998) found that women are less likely to have a defined contribution retirement savings plan, while Agnew (2005) found the opposite. This creates a knowledge gap in literature on the saving culture behaviour across genders.

Women have lower incomes and wealth, on average, and are much more likely to be living in poverty during retirement, so it is important to better understand the factors related to saving among women and how these may differ from those of men. It is against this background that the researcher intends to carry out a study to establish gender differences in saving culture with a special bias on SACCO members.

\subsection{General Objective}

The main objective was to find out if there exists any significance gender difference in the saving culture among SACCO members in Nyandarua County.

\section{Literature Review}

\subsection{Theoretical Framework}

The study will review the life cycle theory, permanent income theory and relative income theory.

\subsubsection{The Life Cycle Theory}

The life cycle theory posits that the main motivation for saving is to accumulate resources for late expenditure and in particular to support consumption at habitual standard during retirement (Modigliani and Brumberg, 1954 and 1980). The basic idea in this theory is that individuals tend to distribute resources to smooth consumption over the life cycle. According to the model saving should be positive for household in their working span and negative for the retired ones and wealth therefore should be hump-shaped.

In the context of the current study, the life cycle theory is relevant in that it appreciates the importance of age in retirement planning. Age is one of the specific objectives in this study. The life cycle hypothesis has been utilized extensively to examine savings and retirement behaviour of older persons. This hypothesis begins with the observation that consumption needs and income are often unequal at various points in the life cycle. Younger people tend to have consumption needs that exceed their income. Their needs tend to be mainly for housing and education, and therefore they have little savings. In middle age, earnings generally rise, enabling debts accumulated earlier in life to be paid off and savings to be accumulated. Finally, in retirement, incomes decline and individuals consume out of previously accumulated savings.

\subsubsection{The Permanent Income Theory}

The permanent income theory states that people will spend money at a level consistent with their expected long term average income (Friedman, 1957). The level of expected long term income then becomes thought of as the level of "permanent" income that can safely be spent. A worker will only save if his or her current income is higher than the anticipated level of permanent income in order to guard against future declines in income. This theory is relevant to the current study because it considers a person's income as a determinant for their retirement planning. In Friedman's permanent income hypothesis model, the key determinant of consumption is an individual's real wealth, not his current real disposable income. Permanent income is determined by a consumer's assets; both physical (shares, bonds, property) and human (education and experience). These influence the consumer's ability to earn income. The consumer can then make an estimation of anticipated lifetime income.

\subsubsection{Relative Income Hypothesis}

Developed by James Duesenberry, the relative income hypothesis states that individual's attitude to consumption and saving is dictated more by his income in relation to others than by abstract standard of living. So an individual is less concerned with absolute level of consumption than by relative levels. The percentage of income consumed by an individual depends on his percentile position within the income distribution (Duesenberry, 1949).

Secondly it hypothesizes that the present consumption is not influenced merely by present levels of absolute and relative income, but also by levels of consumption attained in previous period. It is difficult for a family to reduce a level of consumption once attained (Blau \& Kahn 2006). The aggregate ratio of consumption to income is assumed to depend on the level of present income relative to past peak income.

Relative income hypothesis has important economic implications. Perhaps the most obvious implication is that consumption creates negative externalities in the society, which are not taken into account in individual 
decision-making. According to Koçkesen et al., (2000) if individuals consume, and therefore work, to increase their status, then they will tend to work too much relative to the socially optimal level and hence income taxation could improve the social welfare. Men and women and varying consumption behaviour as such the relative income hypothesis is appropriate for this study

\subsection{Importance of Saving}

Salam and Kurlsam (2001) define savings as the difference between income and consumption. There is an inverse relationship between savings and consumption, other things being equal. Furthermore, the demographic characteristics of the population dictate the saving behaviour of a country (Schultz, 2004). Above all, income distribution is potentially an important factor that determines the capacity to save of the population. On the level of individual households, saving also plays a role as a protection mechanism against the vagaries of economic changes. According to Plessis (2008) such protection is of particular importance in developing economies, where governmental financial protection mechanisms are often lacking. Having cognizance of the importance of household saving as a contributor to a country's domestic saving (and therefore a factor in ensuring financial stability and growth) and as a shield for individual households, as well as the potential negative impact of consumerism on the inflation rate, the low African household saving rate is of significant concern.

Households' savings in financial institutions take the form of savings account, treasury bonds, corporate bonds, shares and stocks, mutual funds, cash value of life insurance, retirement plans and in non-financial assets such as land, houses, vehicles and other real property. Household savings in non-financial assets can be partly explained by the lower transaction costs of acquisition as compared to financial assets and also households ${ }^{\text {ee }}$ perceptions that real assets have higher real rates of return as compared to bank deposits (Carpenter \& Jensen, 2002). In addition, real assets can help households to hedge against domestic inflation (Kiiza \& Pederson, 2002). Financial savings can be held in formal institutions such as banks, in semi-formal financial institutions such as Savings and Credit Cooperative Societies (SACCOs) and Micro Finance Institutions (MFIs), and in informal financial institutions such as rotating savings and credit institutions (ROSCAS). The place where savings are held has a great impact on their transformation into productive investments.

\subsection{Influence of Gender on Personal Savings}

A small but growing body of literature strongly suggests there are gender differences in saving decisions and in risk attitude, at least in some developed countries. Given their divergent social and economic circumstances within and outside the household, Floro and Seguino (2002) observe that women and men may have differing propensities to save at the household level. Since this constitutes the most significant component of gross domestic saves in many developing countries, changes in household saving critically influences aggregate saving rates. If so, shifts in women's relative bargaining power are likely to affect household saving rates, and by extension, domestic saving rates.

Women have experienced substantial labor market gains over the last half century. The gender gap in labor force participation and the gender gap in earnings have both declined. Several factors have been identified as contributing to these gains. First and foremost has been the reduction in the gender gap in education (Blau \& Kahn 2006). Various technological innovations, such as the contraceptive pill, have favored women (Goldin \& Katz 2002). Labor demand has shifted towards industries where female skills are overrepresented (Weinberg 2000, Black \& Juhn 2000). According to (Black \& Brainerd, 2004) better regulatory controls and greater competitiveness have reduced labor market discrimination against women

According to Fisher (2010), as single women live longer in retirement and may have lower earnings and fewer working years to accumulate retirement savings, it is critical to educate women on the importance of establishing a retirement plan. Financial advisors and employee retirement plan professionals need to advise single women with low risk tolerance on less risky investments that will allow them to save comfortably for retirement.

\subsection{Empirical Review}

Gender differences in personal saving behaviors among single person households were investigated using data from the 2007 Survey of Consumer Finances (SCF). Using logistic regression analysis, Fisher (2010) found that women were less likely to save in the short term if they were in poor health, but health made no difference for males. Women with low risk tolerance were less likely to save in the short term and to be regular savers. Education increased males' likelihood of saving in the short term and saving regularly. Mutyaba (2013) drew a comparison between the determinants of household discretionary savings in South Africa and China. The study as well investigated the effect of household savings on the stock market in South Africa and China. Empirical analysis was performed in order to determine the relationship between household savings and various variables, and the effect of household savings on the stock market. Money and quasi money (M2) is the only significant variable and having a negative relationship with household savings in South Africa yet in China, inertia is present the lagged household saving rate is significant. The regression results revealed significance of the explanatory variable household saving in South Africa and insignificance in China. Household savings have an effect on the level of stock market capitalization in South Africa but not in China.

Amu (2008) explored the savings and investment behaviour of rural families in the Ho Municipality of Ghana. The study found that the savings and investment among rural families in the municipality were low and rural households in the Municipality preferred informal forms of savings to the formal forms of savings. There was a negative correlation between 
age and savings as well investment. No significant relationship was found between family size and savings and investment; as well as knowledge in saving and investment as against actual savings and investment of the respondents. Inadequate income, over-reliance on natural conditions and other societal demands were found as constraints to respondents' investment, while inadequacy and fear of safety of income were constraints to their saving. The level of knowledge of respondents on savings and investment was also found to be low. The study concluded that rural households' low saving and investment is the result of economic, social and organizational factors.

Nieuwland (2013) sought to examine the role, if any, that the sex ratio plays as a determinant of the personal saving rate using a simple analysis of 33 countries. Results suggested that, when included in a model with other structural determinants, the sex ratio had a positive, statistically significant effect on the personal saving rate. Further, when examined by age cohort only the sex ratios of the older cohorts were found to be positively and significantly related to personal saving. According to the author, this result contradicts some of the current available theory on sex ratios and saving. Overall, it appears that the sex ratio does have a positive effect on the savings rate and should be included as a structural determinant in future saving rate analyses.

A Malawian study attempted to investigate factors that determine household savings in Malawi overtime. Lihiku (2006) found that the household savings function in Malawi has been unstable overtime and is influenced by factors like income, liabilities, dependence ratio, location and other demographic factors. Female and illiterate managed households are seen to save more on average than their counterparts. Amino et al (2003) they find that the rural Mozambican household saving decisions are responsive to income and amounts of assets owned by the households. They also found that the financial sector plays a crucial role by providing services that local people need. Aryeetey (2004) conducted a study in Ghana seeking to ascertain the assets kept by households and the relationship between choice of assets and the socio economic characteristics of rural households. The findings indicated that female headed households tended to concentrate more on non-farm enterprises while male headed households concentrated more on livestock. Women had more loans and fewer saving in their portfolio as compared to men, possibly due to more involvement in non-farm enterprises that required more capital.

In a study of household saving in Kenya, Njunge (2011) Results showed that savings is positively related to total income, gender and education but negatively to employment status, age and age squared of the household head. Being a male household head indicate that the household saving would increase by Kshs. 2,824.26 while being a female household head, the household saving would increase by Kshs. 13,047.4. Similarly Mukindia (2012) sought to determine the influence of social cultural factors on household savings among Maasai community in Transmara District, Narok County. According to the findings education plays a big role in influencing household savings. Gender also influences household savings; individual 'attitude also determines household savings and the household size determine the level of household savings. Mukhongo (2014) examined the rural household saving situation in Bungoma County with the ultimate goal of providing a tenable answer to the principal policy question of what are the determinants of rural household saving in Bungoma County. The study was organized around three. The framework for analysis involved the estimation of an extended saving model derived from the Permanent Income Hypothesis (Friedman, 1957). The study results indicated that permanent income, education level and wealth significantly contribute to rural household saving in Bungoma County. However, expenditure on children education and landholding significantly lead to negative rural household saving.

\section{Research Methodology}

\subsection{Research Design}

The research adopted a descriptive survey to gather data. Kombo and Tromp (2006) define a descriptive survey as a method of research which gathers data at a particular point in time with the intention of describing the nature of existing conditions of, or determining specific information. Kothari (2004) recommends descriptive design as it allows the researcher to describe, record, analyze and report conditions that exist or existed. The research questions were answered using a mixed method of study design. This involved collecting, analyzing and interpreting both qualitative and quantitative data in the same study or in a series of studies that investigate the same underlying phenomenon. It involved description of the data, in words and tables in order to demonstrate whether there is statistical relationship or merely descriptive in order to answer the research questions in the study.

\subsection{Sampling Procedure and Sample Size}

The choice of sample size is as important as is the choice of sampling scheme. This is because it determines the extent to which the researcher can make statistical or/ and analytical generalizations (Onwuegbuzie \& Leech, 2004).

Krejcie (1970), in the table developed to determine the minimum return sample size for a given population size of 15,000 for a categorical data and a margin of error of 0.05 should yield a sample size of 375 . To arrive at this sample, multi stage sampling procedure was used where sampling was done in stages.

\section{(i) Stage I - Purposive Sampling}

In the first stage Purposive Sampling was used. Purposive Sampling methods is based on some pre-determined characteristic where the researcher selects the sample subjectively based on this characteristic (Patton, 1990). Members of the six SACCOs were purposively selected for the study to form the sampling unit.

(ii) Stage II - Stratified Sampling 
Stratified random sampling was used to sample SACCO members by gender to participate in the study. Stratified sampling technique is a method in which the researcher divides the entire target population into different sub-groups and then randomly selects the final subject proportionally from different sub-groups according to Kothari, (2006). The researcher chose this technique to give each gender equal chance of being selected and thus justifies generalizability of the findings. $39 \%$ and $61 \%$

\section{(iii) Stage III - Random Sampling}

A random sampling technique was then used to select samples from each stratum to take in to considerations the differential gender representation among the SACCO members. Stratification by gender was done as shown in the Table 3.2; Of the 375 respondents, 146 were female and 229 male representing $39 \%$ and $61 \%$ respectively.

Table 1. Sampling Frame.

\begin{tabular}{lllll}
\hline SACCO & $\begin{array}{l}\text { Target } \\
\text { Population }\end{array}$ & Female & Male & $\begin{array}{l}\text { Sample } \\
\text { size }\end{array}$ \\
\hline Nyala Vision SACCO & 2,410 & 25 & 38 & 63 \\
Muki SACCO & 3,673 & 38 & 59 & 97 \\
Olkalau SACCO & 3,890 & 40 & 62 & 102 \\
Jikaze SACCO & 1,210 & 12 & 20 & 32 \\
Taifa SACCO & 1,765 & 18 & 28 & 46 \\
Towers SACCO & 1,321 & 14 & 21 & 35 \\
Total & 14,269 & 147 & 228 & 375 \\
\hline
\end{tabular}

Source: County Co-operative officer, Nyandarua County, 2013

\subsection{Data Collection Method}

After the validity and reliability of the instruments were assessed, the researcher proceeded to the field. A permission letter to carry out the study in the area was sought from the National Council of Science and Technology. These letters helped the researcher to access the Organization, brief the head of operations on the purpose of the study and remove any important information by the managers. The researcher then sought to administer the questionnaires to the respondent and a drop and pick later method was used.

\subsection{Data Analysis}

Data collected from respondents was processed and analyzed. According to Kothari, (2004) this is essential for a scientific study and for ensuring that all relevant data for making contemplated comparisons and analysis are available. The process comprised of; editing which involved examination of raw data to detect errors and omissions in questionnaires and to make corrections where possible; coding which involved assigning numerals to answers so that responses can be classified into a limited number of categories appropriate to the research problem under consideration; classification which involved reducing the data into homogenous groups according to attributes or in class intervals; tabulation which is essentially displaying the data in compact form. A descriptive analysis of the data after processing involved computing mean, mode and median with the help of Statistical Package of Social Sciences Software (SPSS) and Microsoft Excel and presented in frequency tables and charts. Chi-square tests was used to identify relationships between age, income and marital status with saving culture while Mann-Whitney $U$ test was employed in testing for gender differences in saving culture.

\subsection{Analytical Model}

Inferential statistics was used to analyse the collected data. Closed questions were analysed with the help of the Statistical Package for Social Science (SPSS) computer software by assigning numbers to responses. This is approved by Gliner and Morgan (2000) as they find it efficient and it gives straight formal analysis on practically all possible results. In this case, the following model was used to measure the relationship between the dependent variable and independent variable.

$$
Y=f\left(X_{1}, X_{2}, X_{3}\right)
$$

Where

$\mathrm{Y}=$ Saving Culture measure (Annual savings (KShs)

$\mathrm{X}_{1}=$ Income levels

$\mathrm{X}_{2}=$ Marital status

$\mathrm{X}_{3}=$ Level of educations

The multiple regression equation assumes the form;

$\mathrm{Y}=\mathrm{b}_{0}+\mathrm{b}_{1} \mathrm{X}_{1}+\mathrm{b}_{2} \mathrm{X}_{2}+\mathrm{b}_{3} \mathrm{X}_{3}+\mathrm{e}: \mathrm{j}=1,2,3$

Where $b_{0}=$ represent the $y$-intercept.

$b_{j}=j^{\text {th }}$ regression coefficient.

$\mathrm{e}=$ the random error

The magnitude of regression coefficient will help the researcher know the direction and magnitude of the relationship between the independent variables and the dependent variable.

\section{Empirical Results and Discussion}

\subsection{Response Rate}

A total of 375 questionnaires were distributed to the selected respondents in SACCO within Nyandarua County and the response rate was as shown in Table 2.

Table 2. Response Rate.

\begin{tabular}{llll}
\hline SACCO & $\begin{array}{l}\text { Targeted } \\
\text { Sample size }\end{array}$ & Responses & $\begin{array}{l}\text { Response } \\
\text { rate (\%) }\end{array}$ \\
\hline Nyala Vision SACCO & 63 & 63 & 100.0 \\
Muki SACCO & 97 & 76 & 78.4 \\
Olkalau SACCO & 102 & 100 & 98.0 \\
Jikaze SACCO & 32 & 30 & 93.8 \\
Taifa SACCO & 46 & 46 & 100.0 \\
Towers SACCO & 35 & 35 & 100.0 \\
Total & 375 & 350 & 93.3 \\
\hline
\end{tabular}

A total of 350 questionnaires were duly filled and collected making a $93.3 \%$ response rate. This was an acceptable rate and could be attributed to the fact that the questionnaires were physically dropped to the respondents and collected at an agreed date. 


\subsection{Gender Versus Age Brackets}

The study sought to find out the age bracket of respondents in terms of gender and the findings are shown in Table 3.

Table 3. Gender versus Age Brackets.

\begin{tabular}{llll}
\hline & Gender & & \\
\hline Age bracket & Male & Female & Total \\
\hline 21-30 years & $22(10.4 \%)$ & $26(18.8 \%)$ & $48(13.7 \%)$ \\
$31-40$ years & $60(28.3 \%)$ & $58(42.0 \%)$ & $118(33.7 \%)$ \\
41-50 years & $58(27.4 \%)$ & $30(21.7 \%)$ & $88(25.1 \%)$ \\
Over 51 year & $72(34.0 \%)$ & $24(17.4 \%)$ & $96(27.4 \%)$ \\
Total & $212(60.6 \%)$ & $138(39.4 \%)$ & $350(100 \%)$ \\
Chi-square value=18.46 & $\mathrm{DF}=3$ & P-value $=0.001$ & \\
\hline
\end{tabular}

Table 3 , shows that, $42 \%$ of the female respondents were aged $31-40$ years while $28.3 \%$ were male in the same age brackets. About $60.6 \%$ of the respondents were male compared to $39.4 \%$ female. The findings found that there exist strong association between gender and age brackets. The Chi-square value is 18.46 with $\mathrm{P}$-value of $0.001<0.05$. This implies that the association is highly statistically significant with P-value less than 5\% significant level. Gender factor influence age of respondents involved in saving in the SACCO.

\subsection{Gender Versus Academic Qualification}

The study sought to establish whether there is association between gender and education level and the findings are as shown in Table 4.

Table 4. Gender versus Academic Qualification.

\begin{tabular}{|c|c|c|c|}
\hline & Gender & & \\
\hline Education level & Male & Female & Total \\
\hline None & $4(1.9 \%)$ & $4(2.9 \%)$ & $8(2.3 \%)$ \\
\hline Primary & $80(37.7 \%)$ & $46(33.3 \%)$ & $126(36.0 \%)$ \\
\hline Secondary & $98(46.2 \%)$ & $64(46.4 \%)$ & $48(46.3 \%)$ \\
\hline College & $26(12.3 \%)$ & $22(15.9 \%)$ & $48(13.7 \%)$ \\
\hline Undergraduate & $4(1.9 \%)$ & $2(1.4 \%)$ & $6(1.7 \%)$ \\
\hline Total & $212(60.6 \%)$ & $138(39.4 \%)$ & $350(100 \%)$ \\
\hline Chi-square value $=1.74$ & $\mathrm{DF}=4$ & $P$-value $=0.783$ & \\
\hline
\end{tabular}

Table 4 , shows that majority of the respondents $(60.6 \%)$ were males compared to $39.4 \%$ of females. Indeed, $46.3 \%$ of the respondents had attained secondary school academic qualifications and less than $2 \%$ of the respondents had undergraduate qualifications. The study revealed that $2.9 \%$ of the female respondents had no formal qualifications. Also, the study found that there is no significant association between gender and education level. This is evident by the P-value of $0.783>0.05$ significance level. In order the results to be statistically significant the significance level must be less that $5 \%$ allowable error, hence the results in this case are not statistically significant.

\subsection{Gender Versus Marital Status}

The study sought to establish any association between gender and marital status and the responses are as shown in Table 5.

Table 5. Gender and Marital status.

\begin{tabular}{|c|c|c|c|}
\hline & Gender & & \\
\hline Marital status & Male & Female & Total \\
\hline Single & $16(7.6 \%)$ & $34(24.6 \%)$ & $50(14.4 \%)$ \\
\hline Married & $194(92.4 \%)$ & $104(75.4 \%)$ & $298(85.6 \%)$ \\
\hline Total & $210(60.3 \%)$ & $138(39.7 \%)$ & $348(100 \%)$ \\
\hline Chi-square value $=19.60$ & $\mathrm{DF}=1$ & $P$-value $=0.001$ & \\
\hline
\end{tabular}

Table 5, indicates that majority of the respondents $85.6 \%$ were married compared to $14.4 \%$ who were single. The study found that there exist significant association between gender and marital status since the P-value is $0.001<0.05$ significance level. This implies that more married people come from one gender (male) and $24.6 \%$ of female's respondents were not married.

\subsection{Gender Versus Monthly Income}

The study sought to determine the average monthly income by the respondents and the findings are as shown in Table 6 .

Table 6. Gender and Monthly Income.

\begin{tabular}{llll}
\hline \multicolumn{4}{c}{ Gender } \\
\hline Average Income & Male & Female & \\
\hline Ksh 1,001-10,000 & $50(23.6 \%)$ & $46(33.3 \%)$ & $96(27.4 \%)$ \\
Ksh10,001-50,000 & $148(69.8 \%)$ & $74(53.6 \%)$ & $222(63.4 \%)$ \\
Ksh 50,001-100,000 & $8(3.8 \%)$ & $18(13.0 \%)$ & $26(7.4 \%)$ \\
Over Ksh 100,000 & $6(2.8 \%)$ & $0(0 \%)$ & $6(1.7 \%)$ \\
Total & $210(60.6 \%)$ & $138(39.4 \%)$ & $348(100 \%)$ \\
Chi-square value=19.92 & DF=3 & P-value=0.001 & \\
\hline
\end{tabular}

Table 6 , indicate that majority of the respondents $(63.4 \%)$ earn an average of 10,000-50,000 Kenya shillings. Only $1.7 \%$ of the respondents earn over Kshs 100,000. The study found that the average amount earn depends on the gender of the respondents. For instance, none of the female respondents earn more than Kshs 100,000. Also 33.3\% of the respondents earn an average of 1,001-10,000 Kenya shillings compare to $23.6 \%$ of the male respondents who earn the same amount. The results suggest that gender determine the amount earn by a person per month thus more males earn more than females working in the same institution. The P-value $=0.001<0.05$ suggest that there is association between gender and monthly income.

\subsection{Gender Versus Duration of Saving}

The study sought to find out the duration of savings by respondents in terms of gender and the finding are shown in Table 7.

As evident, there exist an association between gender and duration of saving. This implies that male respondents have saved many for a period more than 10 years compared to female respondents. This is supported by $\mathrm{P}$-value $=0.013<0.05$ significance level. Also majority of the respondents (36\%) have embraced saving having saved money for a period of 
5-10 years. Most notably, only $1.4 \%$ of the female respondents have saved for a period of more than 10 years.

Table 7. Gender and Duration of Saving.

\begin{tabular}{llll}
\hline \multicolumn{4}{c}{ Gender } \\
\hline Duration of saving & Male & Female & Total \\
\hline Less than a year & $16(7.5 \%)$ & $20(14.5 \%)$ & $36(10.3 \%)$ \\
1-3 years & $48(22.6 \%)$ & $30(21.7 \%)$ & $78(22.3 \%)$ \\
3-5 years & $50(23.6 \%)$ & $40(29.0 \%)$ & $90(25.7 \%)$ \\
5-10 years & $80(37.7 \%)$ & $46(33.3 \%)$ & $126(36.0 \%)$ \\
Over 10 years & $18(8.5 \%)$ & $2(1.4 \%)$ & $20(5.7 \%)$ \\
Total & $212(60.6 \%)$ & $138(39.4 \%)$ & $350(100 \%)$ \\
Chi-square value $=12.60$ & $\mathrm{DF}=4$ & P-value $=0.013$ & \\
\hline
\end{tabular}

\subsection{Gender Versus Duration of Operating an Account}

The study sought to establish whether there is association between gender and duration of operating an account and the findings are as shown in Table 8.

Table 8. Gender and Duration of Operating an Account.

\begin{tabular}{llll}
\hline & Gender & & \\
\hline $\begin{array}{l}\text { Account operations } \\
\text { durations }\end{array}$ & Male & Female & Total \\
\hline Less than 1 year & $12(6.8 \%)$ & $20(18.5 \%)$ & $32(11.3 \%)$ \\
1-3 years & $56(31.8 \%)$ & $20(18.5 \%)$ & $75(26.8 \%)$ \\
3-5 years & $52(29.5 \%)$ & $32(29.6 \%)$ & $84(29.6 \%)$ \\
5-10 years & $50(28.4 \%)$ & $34(31.5 \%)$ & $84(29.6 \%)$ \\
Over 10 years & $6(3.4 \%)$ & $2(1.9 \%)$ & $8(2.8 \%)$ \\
Total & $176(62.0 \%)$ & $108(38.0 \%)$ & $284(100 \%)$ \\
Chi-square value=13.35 & DF=4 & P-value $=0.001$ & \\
\hline
\end{tabular}

Table 8 , indicates that majority of the respondents $59.2 \%$ have operated an account for a duration of 3-10 years. The study found that there exist significant association between gender and duration of operating an account since the P-value is $0.001<0.05$ significance level. This implies that duration of account operations depend more on the gender of the respondents.

\subsection{Frequency of Saving}

The study sought to establish the trend of saving by the respondents and the findings are as shown in the Figure 1.

This study found that majority of the respondents (over $50 \%$ ) make monthly savings. However, only $1.9 \%$ of female respondents make daily savings. In general majority of the respondents have embraced the culture of saving with SACCO within the Nyandarua County.

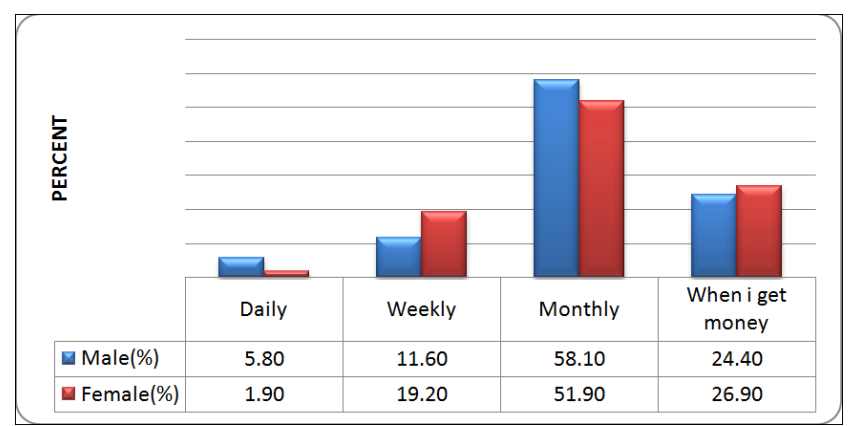

Figure 1. How frequently saving is done by respondents.

\subsection{Average Annual Saving by the Respondents}

This research further attempted to find out the average annual savings by the respondents (in terms of gender) annually and the findings are as shown in Table 9.

Table 9. Average Annual Saving by the Respondents.

\begin{tabular}{|c|c|c|c|}
\hline & Gender & & \\
\hline Average annual saving & Male & Female & Total \\
\hline Less Ksh1,000 & $0(.0 \%)$ & $4(3.7 \%)$ & $4(1.4 \%)$ \\
\hline Ksh $1,000-10,000$ & $40(23.3 \%)$ & $20(18.5 \%)$ & $60(21.4 \%)$ \\
\hline Ksh10,001-50,000 & $68(39.5 \%)$ & $34(31.5 \%)$ & $102(36.4 \%)$ \\
\hline Ksh 50,001-100,000 & $8(4.7 \%)$ & $10(9.3 \%)$ & $18(6.4 \%)$ \\
\hline Over Ksh100,000 & $8(4.7 \%)$ & $4(3.7 \%)$ & $12(4.3 \%)$ \\
\hline $\begin{array}{l}\text { Depend on how much i } \\
\text { have }\end{array}$ & $48(27.9 \%)$ & $36(33.3 \%)$ & $84(30.0 \%)$ \\
\hline Total & $172(61.4 \%)$ & $108(38.6 \%)$ & $280(100 \%)$ \\
\hline Chi-square value $=11.23$ & $\mathrm{DF}=5$ & $P$-value $=0.047$ & \\
\hline
\end{tabular}

In Table 9, it was found that, $36.4 \%$ of the respondents normally saved an average of 10,001-50,000 Kenya shillings annually with the SACCO in Nyandarua County. However, about $30 \%$ of the respondents said that the annual savings depends on how much their have. Furthermore, gender factor influence the average annual saving and results are statistically significant since the $\mathrm{P}$-value $=0.047<0.05$ significance level. This implies that female respondents make more saving than male respondents and vice versus.

\subsection{Financial Decisions}

This research attempted to find out the maker of financial decisions by the respondents and the findings are as shown in Table 10.

Table 10. Financial Decisions.

\begin{tabular}{llll}
\hline & Gender & & \\
\hline $\begin{array}{l}\text { Maker of financial } \\
\text { decisions }\end{array}$ & Male & Female & Total \\
\hline Myself & $110(51.9 \%)$ & $62(44.9 \%)$ & $172(49.1 \%)$ \\
My spouse & $2(0.9 \%)$ & $22(15.9 \%)$ & $24(6.9 \%)$ \\
Both & $100(47.2 \%)$ & $54(39.1 \%)$ & $154(44.0 \%)$ \\
Total & $212(60.6 \%)$ & $138(39.4 \%)$ & $350(100 \%)$ \\
Chi-square value=29.47 & DF=2 & P-value=0.001 & \\
\hline
\end{tabular}

The study found that majority of the respondents $(49.1 \%)$ makes their own financial decisions while $44 \%$ of the respondents' financial decisions are made by both parties. More importantly, gender factor influence financial decisions and the results are highly statistically significant since the $\mathrm{P}$-value $=0.001<0.05$ significance level. The researcher is $99.999 \%$ confidence that financial decisions are based on the gender of the respondents.

\subsection{Multiple Regression Model}

The purpose of this study was to find out if there exists any significance gender difference in the saving culture among SACCO members in Nyandarua County. This was established by regressing income levels, marital status and education level. This section present the results of the analytical model with aim of establishing the predictive equation for this study and 
finding are shown in Table 11

Table 11. Multiple Regression Model Results.

\begin{tabular}{llccrc}
\hline \multirow{2}{*}{ Model } & \multicolumn{2}{c}{$\begin{array}{c}\text { Unstandardized Coefficients } \\
\text { B }\end{array}$} & Std. Error & Beta & Sig. \\
\hline (Constant) & 3.642 & .733 & & 4.969 & .000 \\
Income levels & .355 & .154 & .139 & 2.299 & .022 \\
Marital status & -.543 & .273 & -.121 & -1.990 & .048 \\
Education level & .052 & .125 & .025 & .416 & .678 \\
$\mathrm{R}=0.844$ & & R Squared=0.712 & & Adjusted R Square=0.701 \\
\hline
\end{tabular}

Table 11 shows that income levels influence average annual savings with a B value of 0.355 and a P-value of 0.022 . This implies that an increase of income of the respondents led to an increase in annual saving. The results are statistically significant since $\mathrm{P}$-value $=0.022<0.05$ significance level. In other word, the researcher is $99.978 \%$ confidence that any change in income level will affect annual savings. Marital status of the respondents was also found to be statistically significant in terms of the annual saving with a $B$ value of -0.543 and a $\mathrm{P}$-value of $0.048<0.05$ significance level. This result implies that a change in marital status will affect the annual savings negatively. The researcher is $99.952 \%$ confidence that the change in marital status will negatively have an impact on annual saving by SACCO members in Nyandarua County. The study found that education level has no significant influence on average annual savings by SACCO members in Nyandarua County since the $P$-value $=0.678>0.05$ significance level. Therefore, education level variable will not be included in the predictive model. The predictive model is as follows;

$$
\begin{aligned}
\text { Annual savings } & =3.642+0.355 \text { Income levels } \\
& -0.543 \text { Marital status }
\end{aligned}
$$

The model as shown was modified to exclude the Education level variable. In general, the study found that $71.2 \%$ of the variation can be explained by predictors (Income levels and marital status) and the rest by the other factors beyond the control of the researcher. Further study can be commissioned to approve this finding.

\section{Conclusions and Recommendations}

\subsection{Conclusions}

The purpose of this study was to find out if there exists any significance gender difference in the saving culture among SACCO members in Nyandarua County. This was established by regressing income levels, marital status and education level.

The study found that majority of the respondents earns an average of 10,000-50,000 Kenya shillings. Most notably, 1.7\% of the respondents earn over Kshs 100,000. Also, the study found that income levels influence average annual savings. This implies that an increase of income of the respondents led to an increase in annual saving. The results are statistically significant since P-value $=0.022<0.05$ significance level. In other word, the researcher is $99.978 \%$ confidence that any change in income level will affect annual savings.

Marital status of the respondents was also found to be statistically significant in terms of the annual saving. The result implies that a change in marital status will affect the annual savings negatively. The researcher is $99.952 \%$ confidence that the change in marital status will negatively have an impact on annual saving by SACCO members in Nyandarua County. The study found that majority of the respondents (49.1\%) makes their own financial decisions while $44 \%$ of the respondents' financial decisions are made by both parties.

The study found that education level has no significant influence on average annual savings by SACCO members in Nyandarua County since the $\mathrm{P}$-value $=0.678>0.05$ significance level. Therefore, education level has no significant impact on saving culture by the respondents.

In general, the study found that $71.2 \%$ of the variation can be explained by predictors (Income levels and marital status) and the rest by the other factors beyond the control of the researcher. Further study can be commissioned to approve this finding.

\subsection{Recommendations}

Based on the findings of this study the following recommendations were draw;

The study found that marital status influences the annual saving negatively. The study recommends nurturing of marriage institution as a way of protecting saving culture among women and men members of the SACCO in Nyandarua County.

The study found that education qualification has no significant influence on average annual savings by SACCO members in Nyandarua County. The researcher recommends sensitization of citizen to embrace saving culture. This can be done by the financial institution through public baraza's and educate citizen about important of saving for future use and emergencies cases.

Since the study found that some respondents normally saves money depending on how much they, the research recommend civic education to be conducted among the citizens and especially youth in order to embrace saving culture. Indeed, saving should be done by every account holder irrespective of how much they earn. 


\section{References}

[1] Agnew, J., Szykman, L., Utkus, P., \& Young, J. (2007). Literacy, Trust and 401 (K) Savings Behavior, Center for Retirement Research. Retrieved from https://institutional.vanguard.com/iip/pdfp.CCR Savings Behavior.pdf.

[2] Amino, A. et al, (2003). The Potential for Saving in the Rural Mozambican Households, Savings and Development, Quarterly Review, Issue No. 2

[3] Aryeetey, E. (2004). Household Asset Choice among the Rural Poor in Ghana. Paper presented at the 2004 author's workshop on "Understanding Poverty in Ghana", Institute of Statistical, Social and Economic Research, University of Ghana and Cornell University.

[4] Blau, Francine D. \& Lawrence M. Kahn. (2006). The U.S. gender pay gap in the 1990s: Slowing convergence. Industrial and Labor Relations Review. 60(1): 45-66.

[5] Black, Sandra E. \& Elizabeth Brainerd. (2004). The impact of globalization on gender discrimination. Industrial and Labor Relations Review. 57: 540(59).

[6] Browning, M. and Lusardi, A. (1996). Household Saving: Micro Theories and Micro facts, Journal of Economic Literature, 34(4), pp. 1797-1855.

[7] Carpenter, S., \& Jensen, R. (2002). Household Participation in Formal and Informal Savings Mechanisms: Evidence from Pakistan, Review of Development Economics, 6(3), 314-328.bb.

[8] Duesenberry, J. S. (1949). Income, Saving and the Theory of Consumer Behaviour. Cambridge: Harvard University Press.

[9] Fisher, P. (2010). Gender differences in personal saving behaviors. Journal of Financial Counseling and Planning Education, 21'(1), pp. 14-24.

[10] Floro, M. S., \& Seguino, S. (2002). Gender Effects on Aggregate Saving. Gender and Development: Working Paper Series No. 23.

[11] Goldin at el,. (2002). The power of the pill: Oral contraceptives and women's career and marriage decisions. Journal of Political Economy. 110(4): 730(770).

[12] Government of the Republic of Kenya. (1997). "Cooperatives in a Liberalized Economic Environment.” Session Paper No.6. Nairobi, Kenya. June 1997.

[13] Keynes, J. M. (2006).the general theory of employment, interest and money, Atlantic Publishers \& Distributors.

[14] Kiiza, B., \& Pederson, G. (2002). Household Financial Savings Mobilization: Empirical Evidence from Uganda. Journal of African Economies 10(4), 390-409.

[15] Kombo, D.K., \& Tromp, D.L. (2006). Proposal and Thesis Writing. Nairobi, Pauline.uwi.edu/pdf.

[16] Kothari, C. R. (2004). Research Methodology. New Delhi: Willy Eastern Limited.

[17] Koçkesen, Levent, Efe A. Ok, and Rajiv Sethi. 2000. The Strategic Advantage of Negatively Interdependent Preferences. Journal of Economic Theory 92 (2): 274-299.

[18] Lihiku, N. G. (2006). Determinants of savings in Malawi: a household level analysis. Lilongwe: University of Malawi.

[19] Lincoln,S et el(1985);Naturalistic Inquiry:Beverly Hills CA Sage Publications

[20] Mugenda, O. \& Mugenda, A. (2003). Research methods: Quantitative and qualitative research. Nairobi: Nairobi acts press

[21] Mugenda, A. (2008). Social science research: Theory and principles. Nairobi: Kijabe Printing Press.

[22] Mugenda, A. \& Mugenda, B. (2010) Research Methods Quantitative and Qualitative Approaches. Nairobi: ACTS Press.

[23] Mukhongo, W. (2014). Determinants of Rural Household Savings in Bungoma County - Kenya. Nairobi: Kenyatta University.

[24] Mukindia, S. M. (2012). Influence of socio-cultural factors on households savings among Maasai Community in Transmara District, Narok County. Nairobi: University of Nairobi.

[25] Mulino, F. R. D., \& Chai, D. (2008). On the linkage between financial risk tolerance and risk aversion. Journal of Financial Research, 31(1), 1-23doi: 10.1111/j.1475-6803.2008.00229.x

[26] Nieuwland, J. (2013). Are Savings Sexy? The Role of the Sex Ratio as a Determinant of the Personal Saving Rate. Haverford: Haverford College.

[27] Njung'e, P. M. (2013). Gender And Household Savings Behavior In. Nairobi: University of Nairobi.

[28] Onwuegbuzie, A. J., \& Collins, K. M. T. (2007). A typology of mixed methods samplingdesigns in social science research. The Qualitative Report, 12, 281-316. Retrievedfromhttp://www.nova.edu/ssss/QR/QR12-2/Onwueg buzie2.pdf(35 Seiten)

[29] Orodho, A. \& Kombo,D. (2005). Research Methods. Nairobi: Nairobi: Masola Publishers

[30] Patton, M. (1990). Qualitative evaluation and research methods (pp. 169-186). Beverly Hills, CA: Sage.

[31] Plessis, G. d. (2008). An exploration of the determinants of South Africa's personal savings rate: Why do South African households save so little? Pretoria: University of Pretoria.

[32] Schmidt, L., \& Sevak, P. (2006).Gender, marriage, and asset accumulation in the United States. Feminist Economics, 12(1), 139-166.

[33] Schultz, P. (2004), Demographic Determinants of Savings: Estimating and Interpreting the Aggregate Association in Asia, Centre Discussion Paper No. 901, Yale University.

[34] Strydom, P. (2007). Saving behaviour by South African households, First National Bank, 3.

[35] Sunden, A. E., \&Surrette, B. J. (1998). Gender differences in the allocation of assets in retirement savings plans. American Economic Review, 88, 207-211.

[36] Tesar, L. L. (1991). Savings, investment and international capital flows, Journal of International Economics, 31(1-2), pp. 55-78. 
[37] Weinberg, Bruce A. 2000. Computer use and the demand for female workers. Industrial and Labor Relations Review. 53: $290\{308$.

[38] Williams, M., Tutty, L.M., \& Grinnell, R.M., Jr. (1995). Research in social work (2nd ed.). Itasca, IL: F.E. Peacock.

[39] $\mathrm{Wu}, \mathrm{K}$. (2005). The material consequences of how socialsecurity keeps older persons out of poverty across developed countries. Luxembourg Income Study Working Paper Series.

[40] Yuh, Y., \& Hanna, S. (1997). The Demand for Risky Asset in Retirement Portfolios. Proceedings of the Academy of Financial Services. 